\title{
Somente um ponto de vista*
}

Angela Figueiredo**

É com imensa satisfação que apresento a tradução do artigo What's In a Name: Womanism, Black Feminism and Beyond, de Patrícia Hill Collins, publicado originalmente em 1996 no Black Scholar Journal. O desejo imediato da tradução deste artigo revela um interesse em contribuir com o debate brasileiro atual, dentro $e$ fora dos espaços acadêmicos, sobre o ativismo feminino negro, pois o texto oferece conteúdos importantes da história, da política e da perspectiva emancipatória assumida pelos movimentos afroamericanos em diálogo com a atuação política das mulheres afroamericanas. Nesse sentido, espero que este texto contribua para intensificar o diálogo $e$ o trânsito de ideias entre o norte e sul da diáspora africana. De outro modo, esse texto também revela alguns pontos nevrálgicos da relação dentro da comunidade negra, pois, afinal, por que o nome importa?

De acordo com Sandra Azeredo (1989), os estudos de gênero que se iniciam no Brasil nos anos de 1970 não incorporaram a crítica já realizada por mulheres afro-americanas $e$ pelas mulheres de $\operatorname{cor}^{1}$, já existentes nesse período. E, dentre tantos modos da não incorporação dessa crítica, está a ausência da tradução de títulos que refletem a contribuição de feministas afro-americanas e de feministas do terceiro mundo ao campo de estudos em questão. Como é sabido por todos, a escolha pelos

\footnotetext{
* Recebido em 15 de agosto 2017, aceito em 26 de outubro 2017.

** Professora Adjunta da Universidade Federal do Recôncavo da Bahia (UFRB) e coordenadora do Coletivo Angela Davis. angelaf39@gmail.com

1 O termo mulheres de cor refere-se a feministas não brancas. People of color surge como termo de solidariedade, coalizão de povos racial e etnicamente diferentes, não brancos, na luta contra a supremacia branca nos Estados Unidos e no Canadá, reconhecendo as diferenças nas suas experiências, mas se unindo ao redor de uma experiência compartilhada de racismo sistêmico.
} 
títulos de livros e artigos a serem traduzidos reflete um conjunto de interesses, afinidades teóricas, hierarquias linguísticas, raciais e de gênero - são mais traduzidos os textos publicados em inglês do que em qualquer outra língua, são traduzidos mais textos de autores brancos e mais textos de homens do que mulheres. Enfim, a tradução reflete as estruturas hierárquicas existentes na colonialidade do poder, presentes na geopolítica do conhecimento dentro e fora do território nacional.

Originalmente, o conceito de geopolítica do conhecimento tem sido utilizado para falar da relação entre o centro e a periferia do sistema mundo na produção do conhecimento. Eu quero pensar o conceito a partir da tradução de textos, visto que a tradução é uma das maneiras mais eficazes com que a periferia acessa as ideias, os conceitos, os valores e as representações sobre os outros e sobre si, que são produzidas no centro. No Brasil, até agora, quem tem o poder para escolher o que será publicado em português não tem interesse em traduzir as contribuições teóricas de mulheres negras.

Patrícia Hill Collins é uma proeminente intelectual afroamericana, professora Catedrática da Universidade de Maryland e membro do departamento de African-America Studies, da Universidade de Cincinnati; foi a primeira afro-americana a assumir o posto de Presidente da American Sociological Association. O livro Black Feminist Thought: Knowledge, Consciousness and Politics of Empowerment, originalmente publicado em 1990, projetou a perspectiva crítica de Hill Collins nacional e internacionalmente.

A maioria de nós conheceu Hill Collins por intermédio de Luíza Bairros, em Nossos Feminismos Revisitados (1995), em que a autora propõe uma articulação entre as nossas experiências e a perspectiva apresentada pela intelectual afro-americana. Bairros (1995) considera que uma das grandes contribuições da autora é demonstrar como o conhecimento é produzido por mulheres negras em suas vidas cotidianas, dentro e fora da academia. E é desse modo que um programa de TV é tomado como base para a reflexão proposta no artigo de Bairros (1995:463): 
Assim, através de depoimentos, documentos, letras de música, autobiografias, novelas e textos acadêmicos de mulheres negras, Collins traça um perfil de uma tradição intelectual subjugada também em função de critérios epistemológicos que negam a experiência como base legítima para a construção do conhecimento.

Dessa perspectiva, o pensamento feminista negro é um conjunto de experiências e ideias compartilhadas por mulheres negras que envolve interpretações teóricas da realidade a partir de um ponto de vista.

Posteriormente, o livro de Collins, Black Feminist Thought, circulou entre nós na sua edição em inglês, tornando-se uma leitura obrigatória nos cursos de graduação, pós-graduação e nos espaços não institucionalizados de aprendizado, para tod@s nós. Mas, por que um livro de tamanha importância nunca foi traduzido? Nesse livro, a autora se dedica a estabelecer os fundamentos teóricos e metodológicos do feminismo negro em cinco pontos, assim colocados por Bairros (1995:462): “1) o legado de uma história de luta; 2) a natureza interligada de raça, gênero $e$ classe; 3) o combate aos estereótipos ou imagens de controle; 4) a atuação como mães, professoras e líderes comunitárias; 5) e a política sexual".

Outra contribuição teórica do feminismo negro está no conceito de interseccionalidade, ainda que, para a maioria de nós a formulação desse conceito esteja associada a outra feminista afro-americana, Kimbergele Crenshaw (2002); as bases de articulação do conceito são bem anteriores e recuperam um legado da contribuição das mulheres afro-americanas, sendo importante destacar os trabalhos de Angela Davis (1981) e Hill Collins (2000). Na definição do conceito apresentado por Crenshaw é destacada a

forma pela qual o racismo, o patriarcalismo, a opressão de classe $e$ outros sistemas discriminatórios criam desigualdades básicas que estruturam as posições relativas 
de mulheres, raças, etnias, classes e outras (Crenshaw, 2002:177).

A esse respeito, não podemos deixar de mencionar o pioneirismo de Lélia Gonzalez no texto "Racismo e sexismo na cultura brasileira" (1983).

Certamente, por trás do conceito de interseccionalidade existe uma longa história de formulação teórica da experiência de mulheres negras, a exemplo de Sojourner Truth, que em 1851 formula o seu famoso discurso em que faz a crítica "Ain't a Woman?" ["Por um acaso, não sou uma mulher?"]. Uma tradição continuada por Anna Julia Cooper (1892), que identifica as mulheres negras como importantes agentes da mudança social.

Um outro conceito importante desenvolvido pela autora é o de outsider within que, de acordo com Collins, configura-se em uma posição privilegiada para a compreensão de dinâmicas complexas da vida social. O exemplo mais emblemático é o da empregada doméstica, que na condição de um outro, racializado e inferiorizado, convive e, portanto, compreende os códigos $e$ as dinâmicas cotidianas da vida das famílias de classes médias e das elites brancas sem que seja parte dela. Essa condição permitiu e permite que as trabalhadoras domésticas possam ver a elite branca a partir de uma outra perspectiva, não acessível a mulheres $e$ homens brancos, nem a homens negros.

Não somente no que diz respeito à posição de outsider within, o emprego doméstico sempre foi um ponto crítico para compreender a permanência das relações escravistas nas sociedades modernas, e a sociedade brasileira é um exemplo emblemático disso, uma vez que até muito recentemente, as trabalhadoras domésticas brasileiras não tinham os direitos trabalhistas assegurados como as outras categorias profissionais. Gonzalez (1983), no artigo pioneiro sobre Racismo e sexismo na cultura brasileira, busca entender a neurose da sociedade brasileira, expressa por intermédio de uma relação de amor e ódio vivenciada pelos negros, e denuncia as representações submissas e sexualizadas das mulheres negras, reveladas por meio de três 
figuras emblemáticas: a mãe-preta, a mulata e a trabalhadora doméstica. Tudo isso contribui para o estabelecimento de regras cotidianas pautadas no desrespeito e na exploração dos corpos, do tempo e da negação do direito à vida "privada" das trabalhadoras domésticas (Figueiredo, 2014).

Quando realizei uma pesquisa sobre o emprego doméstico, observei que a maioria das trajetórias narradas pelas trabalhadoras demonstrara que elas tiveram o afeto familiar negado, o acesso à escola impossibilitado, a infância negligenciada e explorada pelo trabalho infantil doméstico $e$ o direito à cidadania não assegurado pelo Estado. Acrescentam-se a esse conjunto de elementos a pertença étnico-racial da maior parte das trabalhadoras domésticas $e$ as representações sobre os corpos das mulheres negras, sempre associados ao servir. Hooks (1995:468) considera que "o sexismo e o racismo, atuando juntos, perpetuam uma iconografia de representação da negra que imprime na consciência cultural coletiva a de que ela está neste planeta principalmente para servir aos outros".

$\mathrm{O}$ que quero dizer com isso, é que a posição de outsider within ocupada pelas trabalhadoras domésticas reflete, por um lado a configuração de uma subjetividade feminina negra marcada pela negação, quer seja da infância, do afeto, da convivência familiar e dos direitos de cidadania assegurados pelo Estado $e$, por outro, indica uma permanente luta por resistir $e$ (re)existir, no sentido de reinventar a si mesma. ${ }^{2}$ Essa posição subalternizada se configura como um espaço importante para observar a realidade. Collins destaca o modo como a literatura e o feminismo negro têm aproveitado esses insights.

Nesse sentido, é que a autora recupera o debate sobre a teoria do ponto de vista, destacando não só o fato de que todo conhecimento é posicionado, mas, principalmente, que o lugar subalternizado ocupado pelas mulheres negras nas estruturas desiguais de poder, permite a essas mulheres compreender melhor as desigualdades sociais. Por paradoxal que pareça, Collins

${ }^{2}$ Sobre o conceito de (re)existir, ver Adolfo Alban (2013). 
considera que esse lugar subalternizado configura-se em um privilégio epistêmico. Todavia, o conceito de outsider within para refletir sobre a nossa presença, a presença de mulheres negras na academia, argumentando que essa posicionalidade pode gerar um ponto de vista diferente em comparação aos paradigmas sociológicos existentes."

Patricia Hill Collins também utiliza o conceito de controle da imagem para falar de representações, no mundo em que a representação das mulheres negras ainda está associada à subalternização, à subserviência $e$ à hipersexualização. Eu compreendo esse conceito também no que ele se refere a emancipação e empoderamento feminino negro, quer dizer, é preciso construir a nossa própria imagem, uma imagem positiva sobre nós, por meio de uma autorrepresentação.

No texto O que é um nome? Womanism, Feminismo Negro e além disso - título da tradução agora publicada, Collins discorre sobre as "diferenças e semelhanças" entre o Womanism e o Blak Feminism, e considera que esse debate reflete o desafio básico de acolher a diversidade das mulheres negras. A importância dos movimentos sociais e das práticas cotidianas para o pensamento crítico existentes no feminismo negro $e$ no pensamento descolonial. Como observado por Catherine Walsh (2013:24):

\begin{abstract}
Stuart Hall argumentó que los momentos políticos producen movimientos teóricos. El interés de Hall no era tanto con una teoría de práctica en el sentido de Bourdieu (1977), sino con la práctica de teorización que emerge y empieza a tomar forma en las luchas por la transformación social, política y cultural, luchas concretas atadas al contexto de su articulación.
\end{abstract}

Ainda que esteja ocorrendo um vigoroso debate no Brasil sobre a identificação de jovens ativistas e intelectuais negras como mulheristas ou feministas negras, até bem pouco tempo atrás a maioria rejeitava o rótulo de feministas, preferindo identificar-se como ativistas ou simplesmente se declaram integrantes dos movimentos de mulheres negras, visto que ainda associam o 
feminismo às mulheres brancas de classe média. ${ }^{3}$ Além disso, no caso brasileiro, de acordo com Lélia Gonzalez (apud Carneiro, 2011:3), o feminismo branco não só omitiu a diferença racial, como compartilhou da crença na democracia racial.

Claudia Pons (2012) analisa as tensões existentes no estabelecimento dos limites de identidade entre o movimento de mulheres e o movimento feminista, e argumenta em prol de uma distinção entre os dois, ainda que considere o movimento de mulheres num sentido bastante amplo. Na definição proposta por Jurema Werneck, e destacada por Pons (2012), a categoria movimento de mulheres negras abriga uma identidade política fortemente construída por essas mulheres, a partir da reivindicação do passado histórico de luta comum. A autora é orientada pela compreensão de que "o enfrentamento ao racismo é fundamental e prioritário", pois se constitui no "principal fator de produção de desigualdades, seja entre mulheres e homens, seja entre mulheres" (Werneck, 2007:1, apud Pons, 2012:239). Desigualdades acentuadas pela força do sexismo $e$ do heterossexismo.

Todavia, o texto de Collins provoca uma reflexão com relação a essa rejeição, já que a autora considera que:

Inserindo o adjetivo "negro" ao feminismo, desafiamos a brancura presumida do feminismo e interrompemos o falso universal deste termo, para mulheres brancas. Uma vez que muitas mulheres brancas pensam que as mulheres negras não têm consciência feminista, o termo "feminista negra" destaca as contradições subjacentes a brancura presumida do feminismo e serve para lembrar às mulheres brancas que elas não são nem as únicas, nem a norma "feminista". (Collins, 1999:13).

Mas, por que o nome dado ao ponto de vista das mulheres negras é tão importante?, indaga Collins no título e ao longo de

${ }^{3}$ Este texto foi originalmente escrito em 2016, um ano depois é significativo o número de mulheres negras que se autodefinem como feministas negras. 
todo o texto. Para a autora, a busca por uma definição para explicitar o ponto de vista crítico das mulheres afro-americanas esconde muito mais do que revela, pois na busca de uma unidade conceitual deixamos de lado, ou perdemos a questão mais importante: compreender como as vozes das mulheres negras coletivamente constroem, afirmam e mantêm um ponto de vista auto definido e dinâmico.

\section{Referências bibliográficas}

ACHINTE, Adolfo Albán. Pedagogias de la re-existência: Artistas indígenas y afrocolombianos. In: WALSH, Catherine (ed.). Pedagogías decoloniales: prácticas insurgentes de resistir, (re)existir y (re)viver. Tombo I, Quito, Ecuador, Ediciones Abya, Yala, 2013, pp.443- 468

BAIRROS, Luiza. Nossos Feminismos Revisitados. Revista Estudos Feministas, Florianópolis, ano 3, $\mathrm{n}^{\circ} 2$, 1995, pp.458-463 [https://periodicos.ufsc.br/index.php/ref/article/viewFile/16462/15034 - acesso em: 22 ago. 2016].

COOPER, Anna Julia. A Voice from the South. Xenia, Ohio, The Aldine Printing House, 1982.

CARNEIRO, Suely. Enegrecer o feminismo: a situação da mulher negra na América latina a partir de uma perspectiva de gênero. 2011. [http://www.unifem.org.br/sites/700/710/00000690.pdf > - acesso em: 18 jan. 2016].

Collins, Patricia Hill. The black feminist thought. London, Routledge, 2000.

. What's in a name? Womanism, Black Feminism, and Beyond. Source: The Black Scholar, vol. 26, $\mathrm{n}^{\circ}$ 1, The Challenge of Blackness, Taylor \& Francis, Ltd. Stable, 1996, pp.9-17 [http://www.jstor.org/stable/41068619].

CRENSHAW, Kimberlé. Documento para o encontro de especialistas em aspectos da discriminação racial relativos ao gênero. Revista Estudos Feministas, Florianópolis, vol. 10, nº 1, 2002, pp.171-189.

DAvis, Angela. Women, Race and Class. New York, NY, Random House, 1981. 
FigueIREDO, Angela. Pec ou a lei áurea dos tempos modernos? Relações de gênero e cidadania tardia para as trabalhadoras domésticas. In: AssIS, Gláucia de Oliveira; MinELLA, Luzinete Simões; FunCK, Susana Bornéo (org.). Entrelugares e mobilidades: desafios feministas. vol. 3, Tubarão, Santa Catarina, Copiart, 2014, pp.289-319.

HOOKS, bell. Intelectuais negras. Revista Estudos Feministas, Rio de Janeiro, IFCS/UERJ, PPCIS/UERJ, vol. 3, n² 2, 1995, pp.464-479.

GonZALEZ, Lélia. Racismo e sexismo na cultura brasileira. Ciências Sociais Hoje 2, Brasília, Anpocs, 1983, pp.223-244.

PONS, Claudia. Outras Falas: Feminismos na perspectiva de mulheres negras brasileiras. Tese (Doutorado em Estudos de Gênero), Programa de Pós-Graduação, Mulher e Feminismo, Universidade Federal da Bahia, Salvador, 2012. (mimeo0,.

WALSH, Catherine (ed.). Pedagogías decoloniales: prácticas insurgentes de resistir, (re)existir y (re) viver. Tombo I. Quito, Ecuador, Ediciones Abya, Yala, 2013. 